\title{
Article
}

\section{GPR55 Antagonist CID16020046 Protects against Atherosclerosis Development in Mice by Inhibiting Monocyte Adhesion and Mac-1 Expression}

\author{
Seung-Jin Lee ${ }^{1}$ and Dong-Soon $\operatorname{Im}^{2, *}$ (1) \\ 1 Department of Pharmacy, College of Pharmacy, Pusan National University, Busan 46241, Korea; \\ leesj@pusan.ac.kr \\ 2 East West Pharmaceutical Research Center, Department of Biomedical and Pharmaceutical Sciences, \\ Graduate School, Kyung Hee University, Seoul 02447, Korea \\ * Correspondence: imds@khu.ac.kr; Tel.: +82-2-961-7399; Fax: +82-2-961-9580
}

check for updates

Citation: Lee, S.-J.; Im, D.-S. GPR55 Antagonist CID16020046 Protects against Atherosclerosis Development in Mice by Inhibiting Monocyte Adhesion and Mac-1 Expression. Int. J. Mol. Sci. 2021, 22, 13084. https:// doi.org/10.3390/ijms222313084

Academic Editor: David Della-Morte

Received: 25 November 2021

Accepted: 2 December 2021

Published: 3 December 2021

Publisher's Note: MDPI stays neutral with regard to jurisdictional claims in published maps and institutional affiliations.

Copyright: (c) 2021 by the authors. Licensee MDPI, Basel, Switzerland. This article is an open access article distributed under the terms and conditions of the Creative Commons Attribution (CC BY) license (https:// creativecommons.org/licenses/by/ $4.0 /)$.

\begin{abstract}
GPR55 recognizes several lipid molecules such as lysophosphatidylinositol. GPR55 expression was reported in human monocytes. However, its role in monocyte adhesion and atherosclerosis development has not been studied. The role of GPR55 in monocyte adhesion and atherosclerosis development was investigated in human THP-1 monocytes and $\mathrm{ApoE}^{-/-}$mice using O-1602 (a potent agonist of GPR55) and CID16020046 (a specific GPR55 antagonist). O-1602 treatment significantly increased monocyte adhesion to human umbilical vein endothelial cells, and the O-1602-induced adhesion was inhibited by treatment with CID16020046. O-1602 induced the expression of Mac-1 adhesion molecules, whereas CID16020046 inhibited this induction. Analysis of the promoter region of Mac-1 elucidated the binding sites of AP- 1 and NF- $\mathrm{kB}$ between nucleotides -750 and -503 as GPR55 responsive elements. O-1602 induction of Mac-1 was found to be dependent on the signaling components of GPR55, that is, Gq protein, $\mathrm{Ca}^{2+}, \mathrm{CaMKK}$, and PI3K. In $\mathrm{Apo}^{-/-}$mice, administration of CID16020046 ameliorated high-fat diet-induced atherosclerosis development. These results suggest that high-fat diet-induced GPR55 activation leads to the adhesion of monocytes to endothelial cells via induction of Mac-1, and CID16020046 blockage of GPR55 could suppress monocyte adhesion to vascular endothelial cells through suppression of Mac-1 expression, leading to protection against the development of atherosclerosis.
\end{abstract}

Keywords: GPR55; CID16020046; atherosclerosis; monocyte adhesion; Mac-1

\section{Introduction}

Atherosclerosis is a major contributor to cardiovascular diseases, including heart failure, myocardial infarction, stroke, and claudication [1,2]. Monocyte adhesion to endothelium is an early event in atherosclerosis in blood vessels $[3,4]$. Subsequently, adherent monocytes penetrate into the intima and differentiate into macrophages, which become foam cells by accumulating modified forms of low-density lipoproteins (LDL) [5]. Chronic inflammation caused by inflammatory stimuli, such as oxidized LDL (oxLDL), accelerates monocyte adhesion to endothelial cells [3-5]. During inflammatory reaction, specific adhesion molecules on the surface of endothelial cells (VCAM-1, ICAM-1, P-selectin, and E-selectin) and monocytes (Mac-1, LFA1, VLA-4, and PSGL-1) mediate the initial loose contact and subsequent tight adhesion [6-8].

GPR55 is recognized as a receptor for lysophosphatidylinositols [9-13] and is also known as an atypical cannabinoid receptor, because a range of endogenous, plant-derived, and synthetic cannabinoid ligands, such as 2-arachidonoylglycerol, palmitoylethanolamide, $\Delta^{9}$-THC, O-1602, and AM251, can activate GPR55 [11,14,15]. GPR55 is highly expressed in human monocytes, which are important inflammatory cells during the initiation and progression of atherosclerosis [16]. Although pro-atherogenic functions of GPR55 in endothelial cells and macrophages have been studied $[17,18]$, the role of GPR55 in monocyte 
adhesion and atherosclerosis development has not yet been investigated. Thus, in this study, the stimulatory roles of GPR55 in atherosclerosis, especially monocyte adhesion to the vascular endothelium and high-fat diet (HFD)-induced plaque formation, were investigated. For this purpose, we employed monocyte adhesion to human umbilical vein endothelial cells (HUVECs) and HFD-induced atherosclerosis development in ApoE knockout (KO) mice along with O-1602 as a GPR55 agonist [15,19] and CID16020046 as a specific GPR55 antagonist [20].

\section{Results}

\subsection{O-1602 Induced Adhesion of THP-1 Monocytes to HUVECs}

Monocyte adhesion to endothelial cells is a key stage in the initiation of atherosclerosis, and adhesion is dependent on the interaction between adhesion molecules on monocytes and endothelial cells $[4,5]$. To investigate the role of GPR55 in monocyte adhesion to endothelial cells, THP-1 human monocytic cells were treated with O-1602 (a selective GPR55 agonist) and co-cultured in HUVECs. Treatment with O-1602 induced the adhesion of THP-1 monocytes to HUVECs in a dose-dependent manner (Figure 1A,B). Monocyte adhesion to endothelial cells induced by O-1602 was inhibited by CID16020046 (a selective GPR55 antagonist) in a concentration-dependent manner (Figure 1C,D), suggesting that GPR55 is involved in monocyte adhesion to endothelial cells.

A

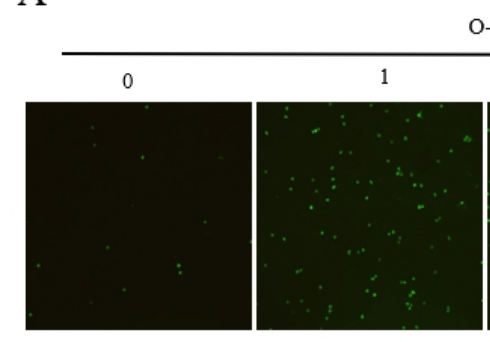

O-1602
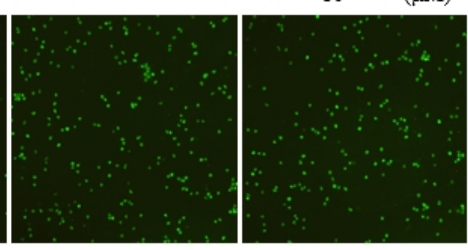

$\mathrm{C}$
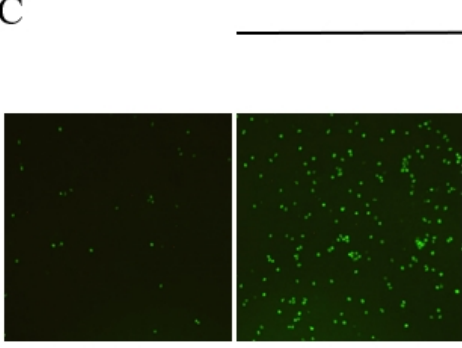

O-1602, $10 \mu \mathrm{M}$

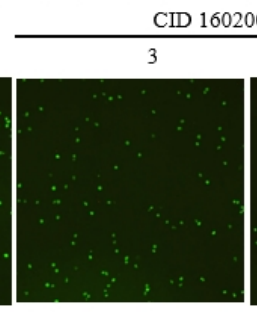

$\mathrm{B}$

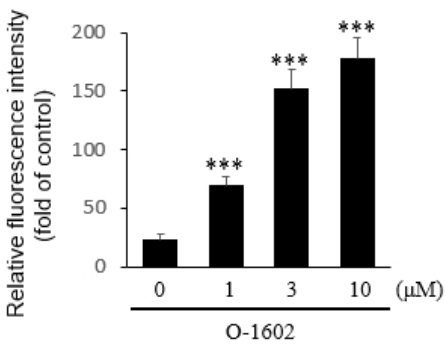

$\mathrm{D}$

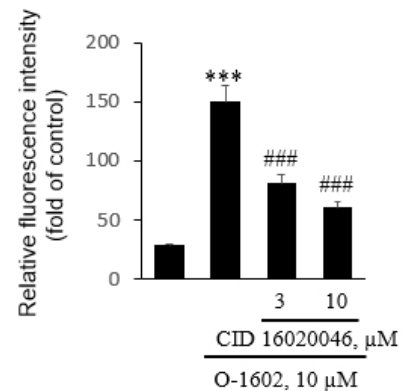

Figure 1. Effects of a GPR55 agonist, O-1602, on THP-1 monocytes adhesion to endothelial cells. THP-1 cells were treated with the indicated concentration of O-1602 for $24 \mathrm{~h}$ and labeled with $0.2 \mathrm{mg} / \mathrm{L}$ calcein-AM for $30 \mathrm{~min}$ at $37^{\circ} \mathrm{C}$. The labeled cells were seeded onto confluent HUVECs and images were obtained after $2 \mathrm{~h}$ using an inverse optical microscope (Axiovert 25) and Axio Vision Release 4.7 software (A) Representative fluorescence microscopic images of THP-1 monocyte adhesion to endothelial cells. (B) Histogram of THP-1 monocyte adhesion to endothelial cells THP-1 cells were treated with the indicated concentration of O-1602 for $24 \mathrm{~h}$. (C,D) THP-1 cells were treated with CID16020046 for $1 \mathrm{~h}$ and then with the indicated concentration of O-1602 for $24 \mathrm{~h}$. (C) Representative fluorescence microscopic images of THP- 1 monocyte adhesion to endothelial cells. (D) Histogram of THP-1 monocyte adhesion to endothelial cells. The results are representative of four independent experiments. The results are presented as the mean $\pm \mathrm{SEM}$ of four independent experiments. Statistical significance: ${ }^{* * *} p<0.01$ vs. untreated control cells, \#\#\# $p<0.001$ vs. O-1602-treated cells. 


\subsection{Involvement of $\mathrm{Gq} / 11$ Proteins, $\mathrm{Ca}^{2+}, \mathrm{CaMKK}$, and PI3K in GPR55-Mediated Monocyte Adhesion}

We explored how GPR55 activation leads to monocyte adhesion to HUVECs. The signaling components of GPR55 activation have been reported to be Gq proteins, phospholipase $\mathrm{C}$, an increase in cytosolic $\mathrm{Ca}^{2+}$ concentration, and subsequent protein kinases $[10,11,21]$. Therefore, we utilized YM254890 (an inhibitor of Gq proteins), BAPTA-AM (an intracellular $\mathrm{Ca}^{2+}$ chelator), STO609 (an inhibitor of the $\mathrm{Ca}^{2+} /$ calmodulin-dependent protein kinase kinase (CaMKK)), and LY294002 (an inhibitor of PI3K). As shown in Figure $2 \mathrm{~A}, \mathrm{~B}$, the signaling pathway of $\mathrm{Gq} / \mathrm{Ca}^{2+} / \mathrm{CaMKK}$ was found to be partly involved in GPR55-mediated monocyte adhesion. That is, O-1602 induced monocyte adhesion was suppressed by the presence of YM254890, BAPTA, and STO-609 (Figure 2A,B). Additionally, the increased adhesion of THP-1 cells by O-1602 treatment was inhibited by LY294002 (Figure 2C,D). Therefore, it is suggested that GPR55 activation leads to the signaling cascade of $\mathrm{Gq} / \mathrm{Ca}^{2+} / \mathrm{CaMKK}$ and PI3K for the induction of monocyte adhesion to endothelial cells.

A
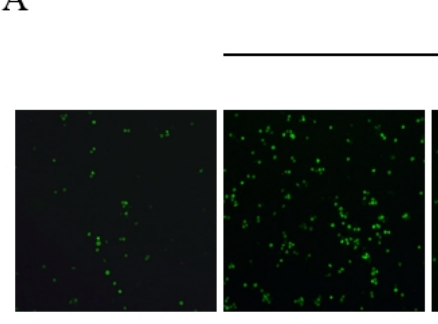

$\mathrm{C}$
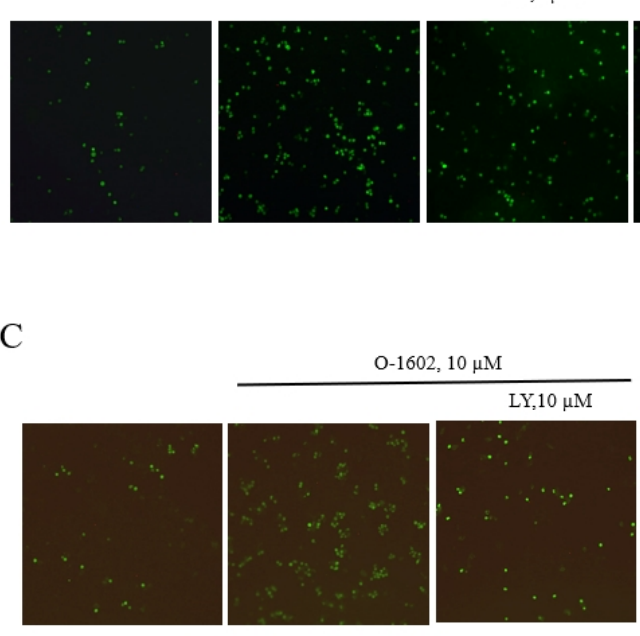

$\mathrm{O}-1602,10 \mu \mathrm{M}$
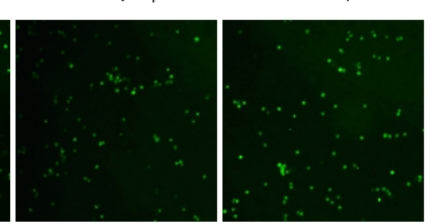

$\mathrm{D}$

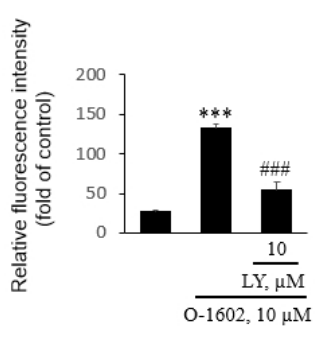

B

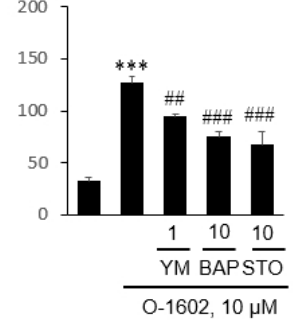

Figure 2. Effects of YM254890, BAPTA-AM, STO-609, and LY294002 on O-1602-induced THP-1 monocytes adhesion to endothelial cells. THP-1 cells were pretreated with the indicated concentrations of inhibitors for $1 \mathrm{~h}$, and then treated with $10 \mu \mathrm{M} \mathrm{O}-1602$ for $24 \mathrm{~h}$. The calcein-labeled cells were seeded onto confluent HUVECs and images were obtained after $2 \mathrm{~h}$. (A) Representative fluorescence microscopic images of THP-1 monocyte adhesion to HUVECs in the presence of YM254890, BAPTA-AM, and STO-609. (B) Histogram of THP-1 monocyte adhesion to endothelial cells in the presence of YM254890, BAPTA-AM, and STO-609. (C) Representative fluorescence microscopic images of THP-1 monocyte adhesion to HUVECs treated with LY294002. (D) Histogram of the adhesion of THP-1 monocytes to endothelial cells with LY294002. The results are presented as the mean \pm SEM of three independent experiments. Statistical significance: ${ }^{* * *} p<0.001$ vs. untreated control cells, \#\# $p<0.01$, \#\# $p<0.001$ vs. O-1602-treated cells.

\subsection{Activation of GPR55-Induced Mac-1 Expression in THP-1 Cells}

Next, we investigated how GPR55 activation induces monocyte adhesion by examining the expression of adhesion molecules in THP-1 monocytes. Among adhesion molecules of the monocyte membrane, GPR55 activation induced Mac-1, but not other adhesion molecules, such as LFA1-1, VLA-4, and PSGL-1 (Figure 3A), and the induction of Mac-1 was found to be concentration-dependent (Figure 3B). In order to confirm the effect of GPR55 activation on the mRNA expression of Mac-1, its protein levels were checked by flow cytometry. It was found that O-1602 induced the protein expression of Mac-1 (Figure 3C), and the induction of Mac-1 was concentration-dependent (Figure 3D). Pretreatment with CID16020046 suppressed the O-1602-induced mRNA expression and protein expression of 
Mac-1 in a concentration-dependent manner (Figure 4), demonstrating the involvement of GPR55 in Mac-1 expression in monocytes.

A

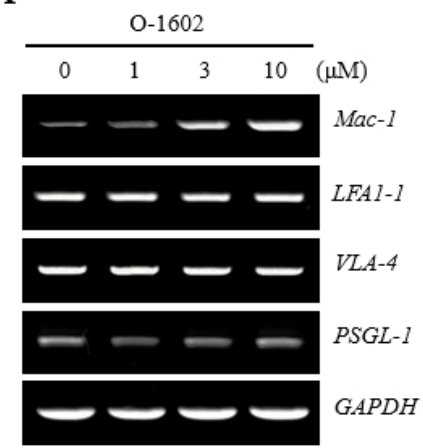

$\mathrm{C}$

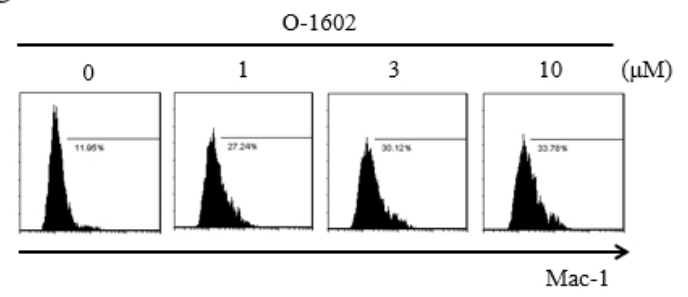

B

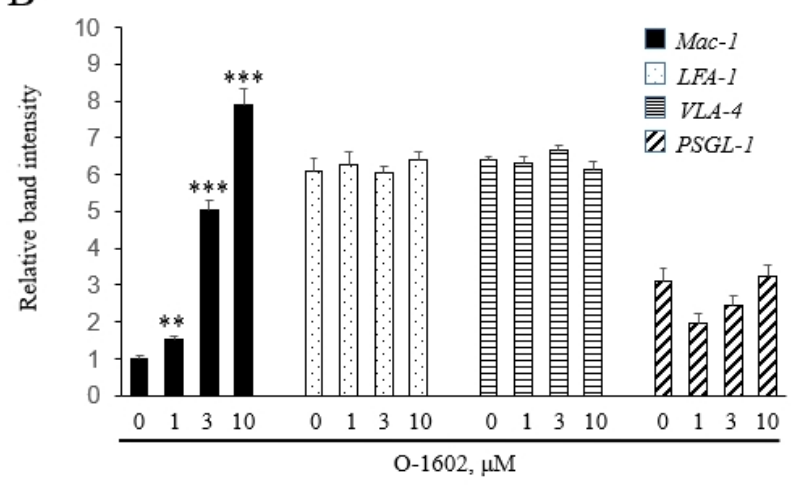

$\mathrm{D}$

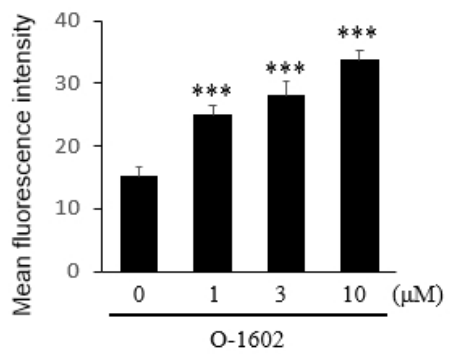

Figure 3. Effects of O-1602 on the expression of adhesion molecules in THP-1 cells. THP-1 cells were treated with the indicated concentration of O-1602 for $24 \mathrm{~h}$. The mRNA expression of adhesion molecules was analyzed by RTPCR. (A) Representative RT-PCR images. (B) Histograms showing the relative mRNA levels. (C) Representative flow cytometry images of Mac-1 protein. (D) Histograms showing relative Mac-1 protein levels. The results are presented as the mean \pm SEM of three independent experiments. Statistical significance: ${ }^{* *} p<0.01,{ }^{* * *} p<0.001$ vs. untreated control cells.

A

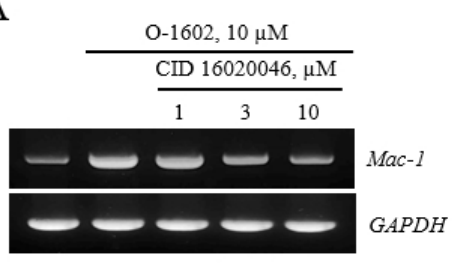

$\mathrm{C}$

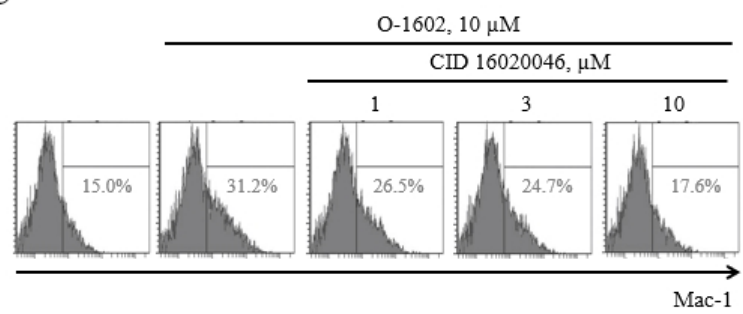

B

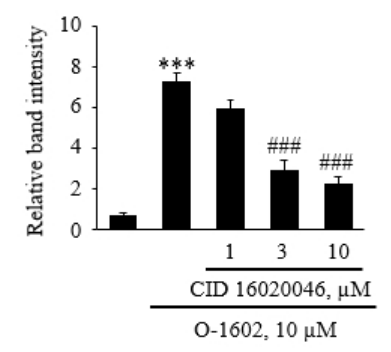

$\mathrm{D}$

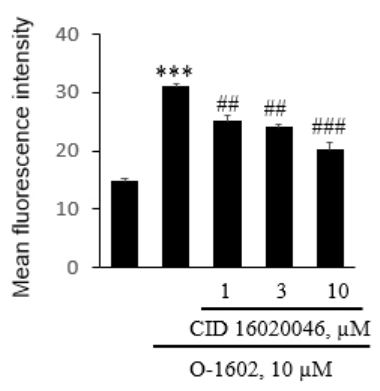

Figure 4. Effects of CID16020046 on GPR55-mediated Mac-1 expression in THP-1 cells. THP-1 cells were pretreated with the indicated concentrations of CID16020046 for $1 \mathrm{~h}$, and then treated with $10 \mu \mathrm{M}$ O-1602 for $24 \mathrm{~h}$. The mRNA expression of adhesion molecules was analyzed by RT-PCR and flow cytometry. (A) Representative RT-PCR images. (B) Histograms showing the relative mRNA levels. (C) Representative flow cytometry images of Mac-1 proteins. (D) Histograms showing relative Mac-1 protein levels. The results are presented as the mean \pm SEM of three independent experiments. Statistical significance: ${ }^{* * *} p<0.001$ vs. untreated control cells, \#\# $p<0.01$, \#\# $p<0.001$ vs. O-1602-treated cells. 


\subsection{Involvement of Gq/11 Proteins, Ca2+, CaMKK, and PI3K in GPR55-Mediated Mac-1 Expression}

We investigated whether the signaling components of GPR55 lead to Mac-1 expression in monocytes using pharmacological inhibitors. As shown in Figure 5A,B, GPR55-mediated expression of Mac-1 mRNA was suppressed by the presence of YM254890, BAPTA, and STO-609 (Figure 5A,B). These inhibitions were further confirmed at the protein level by flow cytometry (Figure 5C,D).

A

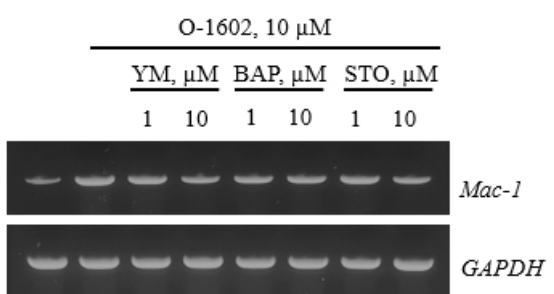

B

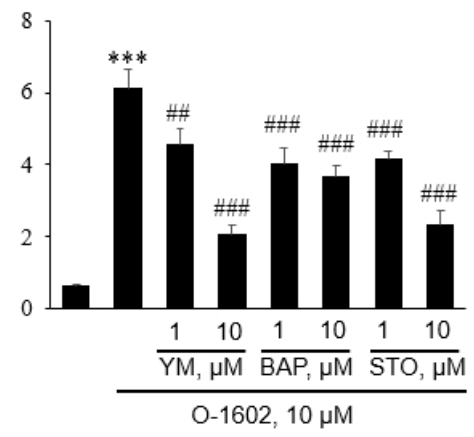

$\mathrm{C}$

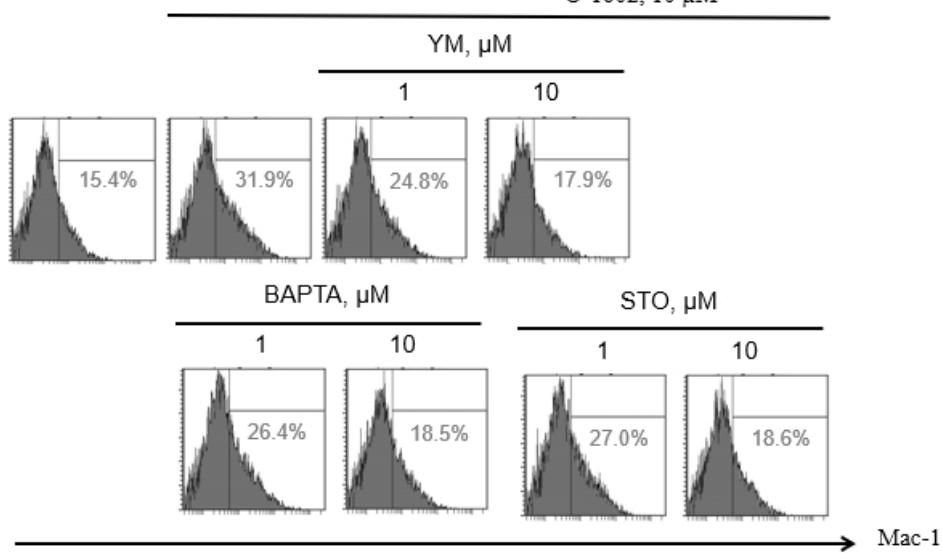

$\mathrm{D}$

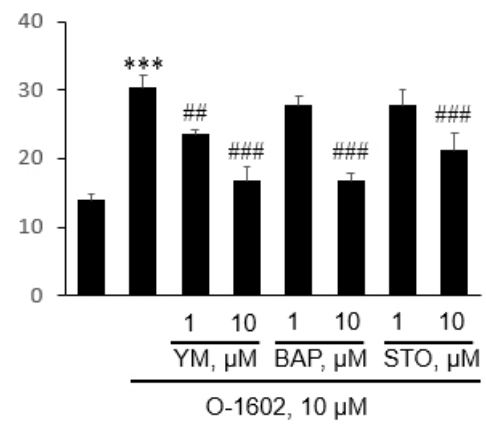

Figure 5. Effects of YM254890, BAPTA-AM, and STO-609 on O-1602-induced Mac-1 expression in THP-1 cells. THP-1 cells were pretreated with the indicated concentrations of inhibitors for $1 \mathrm{~h}$, and then treated with $10 \mu \mathrm{M} \mathrm{O}-1602$ for $24 \mathrm{~h}$. The mRNA expression of adhesion molecules was analyzed by RT-PCR and flow cytometry. (A) Representative RT-PCR images. (B) Histograms showing the relative mRNA levels. (C) Representative flow cytometry images of Mac-1 proteins. (D) Histograms showing relative Mac-1 protein levels. The results are presented as the mean \pm SEM of three independent experiments. Statistical significance: ${ }^{* * *} p<0.001$ vs. untreated control cells, \#\# $p<0.01$, \#\#\# $p<0.001$ vs. O-1602-treated cells.

Additionally, Mac-1 expression by O-1602 treatment in monocytes was inhibited by LY294002 at the mRNA and protein levels (Figure 6). Therefore, GPR55 activation induces Mac-1 expression through signaling cascades of $\mathrm{Gq} / \mathrm{Ca}^{2+} / \mathrm{CaMKK}$ and PI3K in monocytes.

\subsection{Cloning and Characterization of the Mac-1 Promoter Involved in O-1602-Induced Mac-1 Transcription}

To locate the region responsible for GPR55-induced Mac-1 transcription, luciferase activity was conducted after transiently transfecting six constructs with different sizes of the $2010 \mathrm{nt}$ promoter region of Mac-1. As shown in Figure 7A, the luciferase reporter activity of pMac1-2010 was higher in several constructs after O-1602 treatment than that in the control. Among five constructs, the promoter containing nucleotides from nt -750 to $\mathrm{nt}-503$ showed the strongest induction in response to O-1602 (Figure 7A). This suggests that the region between $\mathrm{nt}-750$ and $\mathrm{nt}-503$ is responsible for GPR55-induced Mac-1 transcription 
in monocytes. Sequence analysis within this region demonstrated the presence of consensus elements for transcription factors, including AP-1 and NF- $\mathrm{kB}$ (Figure 7B).

A

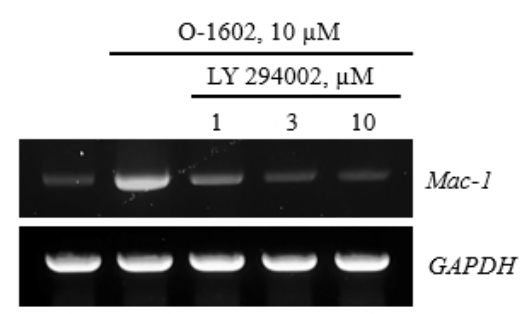

C

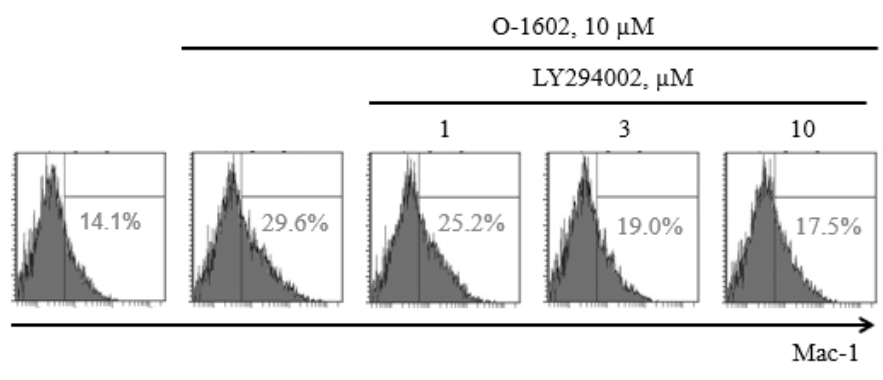

$\mathrm{B}$

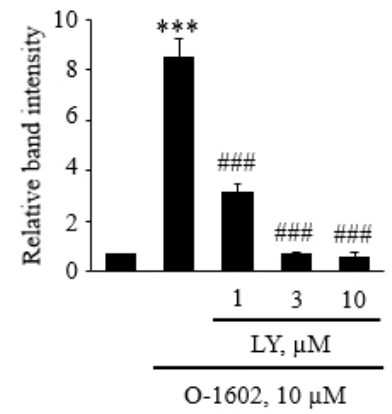

$\mathrm{D}$

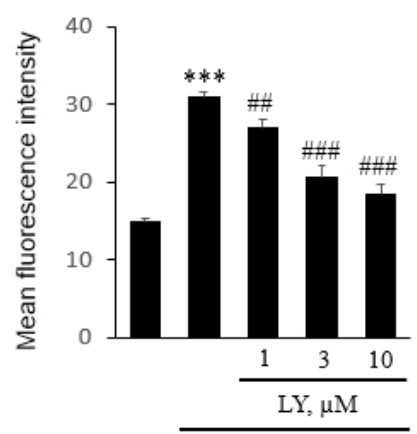

$0-1602,10 \mu \mathrm{M}$

Figure 6. Effects of LY294002 on O-1602-induced Mac-1 expression in THP-1 cells. THP-1 cells were pretreated with the indicated concentrations of LY294002 for $1 \mathrm{~h}$, and then treated with $10 \mu \mathrm{M}$ O-1602 for $24 \mathrm{~h}$. mRNA expression of adhesion molecules was analyzed by RT-PCR and flow cytometry. (A) Representative RT-PCR images. (B) Histograms showing the relative mRNA levels. (C) Representative flow cytometry images of Mac-1 proteins. (D) Histograms showing relative Mac-1 protein levels. The results are presented as the mean \pm SEM of three independent experiments. Statistical significance: *** $p<0.001$ vs. untreated control cells, \#\# $p<0.01$, \#\#\# $p<0.001$ vs. O-1602-treated cells.

\subsection{Involvement of AP-1 and NF- $\kappa B$ in GPR55-Induced Mac-1 Transcription}

To assess whether GPR55 activation induced binding of AP-1 and NF- $\mathrm{kB}$ to the responsive sites, luciferase constructs containing tandem repeats of consensus sequences of AP-1 or NF- $\mathrm{kB}$ were used. The O-1602 treatment induced an increase in luciferase activity in pAP-1-Luc and pNF-kB-Luc, and these increases were suppressed by the CID16020046 treatment (Figure 8A,B), confirming that GPR55 activation leads to Mac-1 transcription via binding of AP-1 and NF- $\mathrm{KB}$ to the responsive sites in the promoter region of Mac-1. Next, we performed ChIP assays to directly assess whether GPR55 activation induced binding of AP-1 and NF- $\mathrm{kB}$ to the binding sites of the Mac-1 promoter region. After nuclear extraction from monocytes treated with O-1602 or O-1602 plus CID16020046, protein-DNA complexes were immunoprecipitated with anti-AP-1 or anti-NF- $\mathrm{kB}$ antibodies. Subsequent PCR amplification of the Mac-1 promoter showed increases in AP- 1 and NF- $\mathrm{KB}$ binding to the Mac-1 promoter after the O-1602 treatment (Figure $8 \mathrm{C}$ ). The increased binding was suppressed by CID16020046 treatment in a dose-dependent manner (Figure 8C,D), demonstrating that the binding of AP-1 and NF- $\mathrm{kB}$ participates in GPR55-mediated induction of Mac-1 expression. 
A

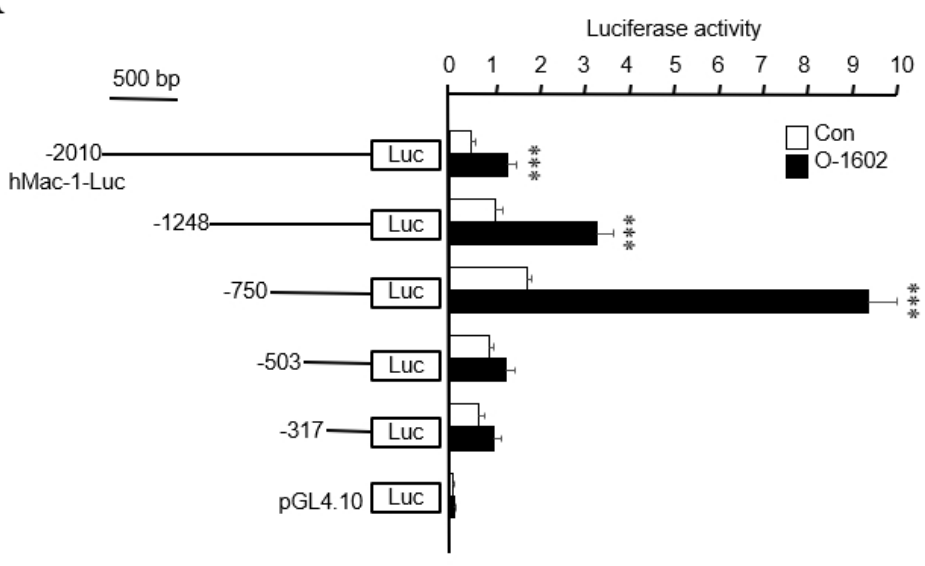

B

-750 GAGCTCAAACAATCCTCCTGCCTCAGCCTCTGGAGTAGCTAGGACTACAGGCATGTGCC
AP1
ACCATGCCTGGCTAATTTTTAAATGTATTTTTTTGTAGAGTCGGGGTCTCCCTATGTTGC
NCAGGBCTGGAGTGCAGTGGTGTGATCCTAGCTCACTGCAGCCTGGACCTCGGGCTCAAG
TAATTCTCACACCTCAGCCTGTCCAGTAGCAGGGGCTACAGGCGCGCACCACCATGCCCA
GCTAATTAAAAATATT -503

Figure 7. Cloning and characterization of the Mac-1 promoter involved in GPR55-mediated Mac-1 transcription. (A) THP-1 cells were co-transfected transiently with various promoter constructs and an empty luciferase vector pGL4.10 for $24 \mathrm{~h}$, and then treated with or without $10 \mu \mathrm{M} \mathrm{O}-1602$ for $24 \mathrm{~h}$. The relative luciferase activity was presented as means \pm SE of five independent experiments. Statistical significance: ${ }^{* *} p<0.001$ vs. untreated control cells. (B) Nucleotide sequence of the promoter region of the Mac- 1 gene. The sequence of the region between $\mathrm{nt}-750$ and $-503 \mathrm{bp}$ of the $5^{\prime}$-flanking region is shown. The underlined sequences are possible transcription factor binding sites, as predicted by TFSEARCH.

2.7. Involvement of $\mathrm{Gq} / 11$ Proteins, $\mathrm{Ca}^{2+}, \mathrm{CaMKK}$, and PI3K in GPR55-Induced Inductions of $A P-1$ and $N F-\kappa B$

We investigated the signaling components of GPR55-induced induction and binding of AP-1 and NF- $\mathrm{kB}$ to the promoter region of Mac-1. The same signaling components of GPR55 activation, that is, Gq proteins, phospholipase C, increase in cytosolic $\mathrm{Ca}^{2+}$ concentration, and subsequent protein kinases, were studied with inhibitors of YM254890, BAPTA-AM, STO609, and LY294002. As shown in Figure 9, the signaling pathway of $\mathrm{Gq} / \mathrm{Ca}^{2+} / \mathrm{CaMKK}$ was found to be involved in the GPR55-mediated induction of AP-1 and NF- $\mathrm{KB}$, which was demonstrated by the fact that O-1602-induced increase of luciferase activities in pAP-1-Luc and pNF-KB-Luc was suppressed by the presence of inhibitors (YM254890, BAPTA-AM, and STO609) (Figure 9A,B). Additionally, increased binding of AP1 and NF- $\mathrm{KB}$ to the Mac-1 promoter region was found to be mediated through the signaling pathway of $\mathrm{Gq} / \mathrm{Ca}^{2+} / \mathrm{CaMKK}$ in the ChIP assays (Figure $9 \mathrm{C}-\mathrm{E}$ ). Similarly, the presence of LY294002 suppressed GPR55-mediated induction of AP-1 and NF- $k B$ (Figure 10A,B). Furthermore, direct binding of AP-1 and NF- $\mathrm{KB}$ to the Mac-1 promoter region by GPR55 activation was also suppressed by LY294002 in the ChIP assays (Figure 9C-E). Therefore, GPR55 activation is suggested to signal the cascade of $\mathrm{Gq} / \mathrm{Ca}^{2+} / \mathrm{CaMKK}$ and PI-3K for the induction of AP-1 and NF- $\mathrm{kB}$ and direct binding of AP-1 and NF- $\mathrm{kB}$ to the Mac-1 promoter region in monocytes. 
A

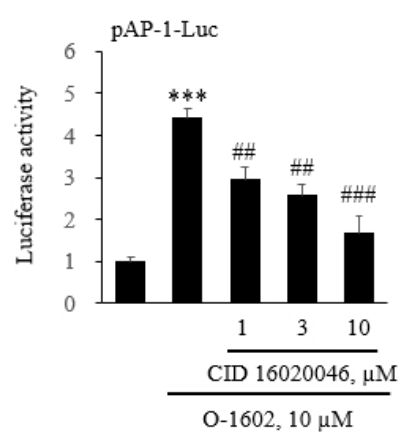

$\mathrm{C}$

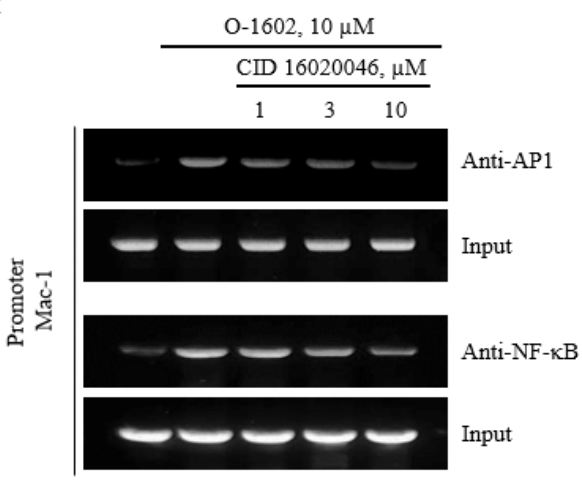

B

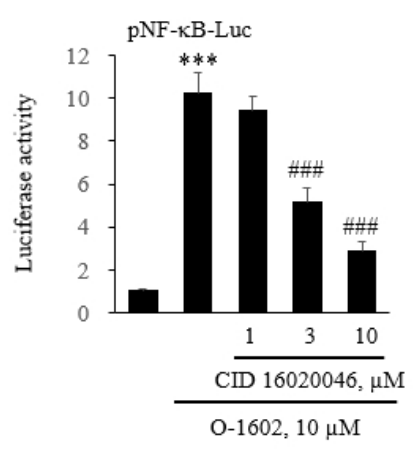

$\mathrm{D}$

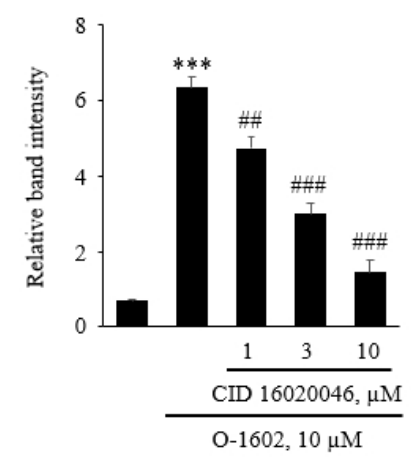

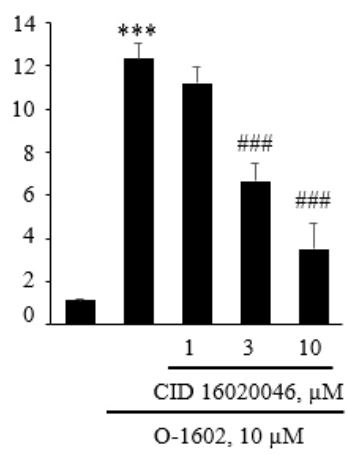

Figure 8. Involvement of AP-1 and NF- KB in GPR55-mediated Mac-1 transcription. (A,B) THP-1 cells were transfected with luciferase reporter constructs containing AP-1 or NF- $\mathrm{KB}$ consensus binding sites, pretreated with the indicated concentrations of CID16020046 for $1 \mathrm{~h}$, and then treated with $10 \mu \mathrm{M}$ O-1602 for $24 \mathrm{~h}$. The AP-1 (A) and NF- $\mathrm{KB}$ (B) luciferase activities were represented as the mean \pm SEM from five to six independent experiments. (C,D) Binding of AP-1 and NF- $K B$ to the $M a c-1$ promoter was detected with the chromatin immunoprecipitation (ChIP) assay. Immunocomplexes of AP-1 and NF- $\mathrm{kB}$ associated with DNA were obtained from THP-1 cells. The THP-1 cells were pretreated with the indicated concentrations of CID16020046 for $1 \mathrm{~h}$, and then treated with $10 \mu \mathrm{M} \mathrm{O}-1602$ for $24 \mathrm{~h}$. Specific DNA fragments were quantified by PCR, as detailed in the Methods section. DNA purified from lysates incubated without antibody was used as input control (Input). Representative images $(C)$ and quantitated histograms of the ChIP assay. The results are presented as means \pm SEM of three independent experiments. Statistical significance: ${ }^{* * *} p<0.001$ vs. non-treated control cells, \#\# $p<0.01$ and \#\#\# $p<0.001$ vs. O-1602-treated cells.

\subsection{Inhibition of GPR55 Ameliorated Atherosclerosis Development in an ApoE KO Mouse Model}

Based on the results of the in vitro cell experiments, a high-fat diet (HFD)-induced model of atherosclerosis development was used in ApoE KO mice. Male ApoE KO mice were fed a normal diet (ND) for 16 weeks. Mice were then fed an ND or HFD for 8 weeks (Figure 11A). Another group of mice, that is, the HFD plus CID16020046 group, was fed the HFD for 8 weeks, and at the same time, treated with CID16020046 (1 mg/kg, i.p., five times per week) for 8 weeks (Figure 11A). The HFD induced an increase in the body weight and plasma glucose level by $30 \%$ and $64 \%$, respectively, but decreased HDL cholesterol levels by $41 \%$ (Table 1). The HFD induced an increase in the plasma total cholesterol, LDL cholesterol, and triglycerides by 290\%, 401\%, and 159\%, respectively (Table 1). CID16020046 administration suppressed the increase in body weight and plasma glucose level by $86 \%$ and $66 \%$, respectively, but increased HDL levels by 127\%. Furthermore, CID16020046 administration suppressed the increase in plasma total cholesterol, LDL cholesterol, and triglycerides by $79 \%, 81 \%$, and 84\%, respectively. Therefore, inhibition of GPR55 improved all the harmful parameters induced by HDF, that is, body weight, glucose level, total cholesterol, LDL cholesterol, HDL cholesterol, and triglycerides. These improvements were further confirmed by histological analysis of the atherosclerotic plaques. As shown in Figure 11B,C, narrowed vessels and increased plaque thickness were observed in the HFD group, and CID16020046 treatment inhibited vessel narrowing and plaque thickening. 
Oil red O staining showed severe lipid accumulation in the plaque of HFD-fed mice and reduction of lipid accumulation in the plaque of CID16020046-treated mice (Figure 11B).

A

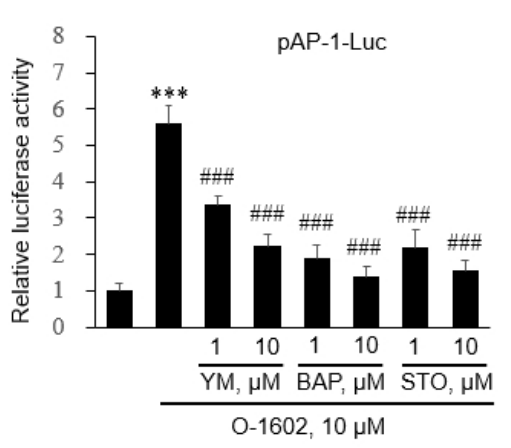

$\mathrm{C}$

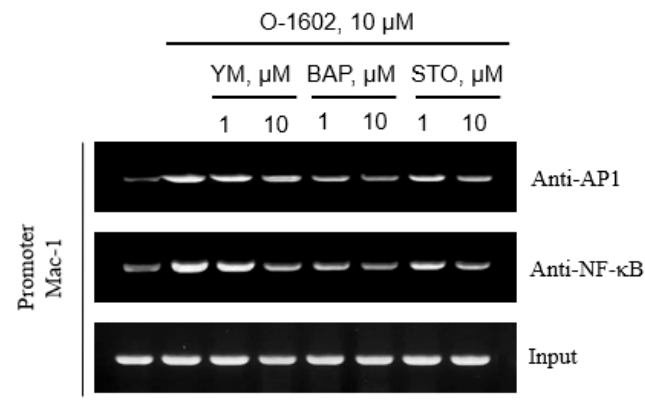

B

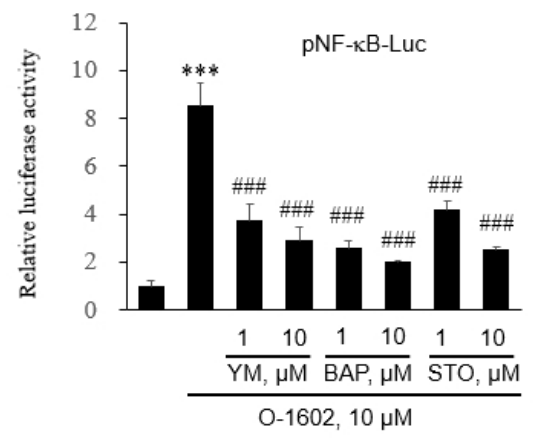

$\mathrm{D}$

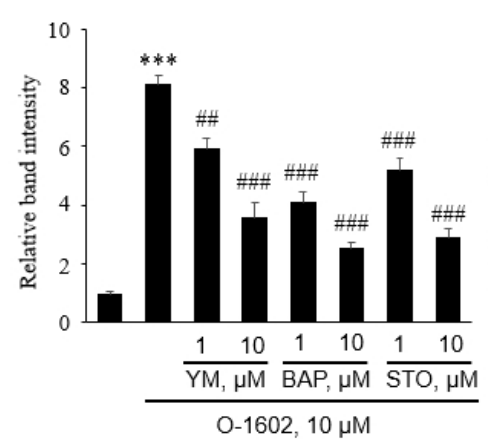

E

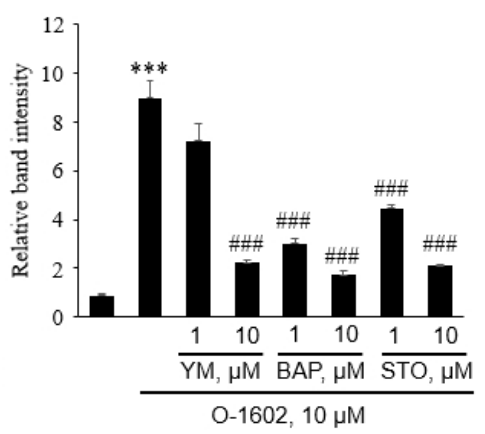

Figure 9. Effects of YM254890, BAPTA-AM, and STO-609 on O-1602-induced expression of AP-1 and NF-kB in THP-1 cells. THP-1 cells were pretreated with the indicated concentrations of inhibitors for $1 \mathrm{~h}$, and then treated with $10 \mu \mathrm{M} \mathrm{O}-1602$ for $24 \mathrm{~h}$. Mac-1 mRNA, promoter activity, and protein expression were analyzed by reporter gene assay and chromatin immunoprecipitation (ChIP) assay. The AP-1 (A) and NF-B (B) luciferase activities are represented as the mean \pm SEM from five to six independent experiments. (C-E) Binding of AP-1 and NF- $\mathrm{KB}$ to the Mac-1 promoter was detected by ChIP assay. Representative images $(C)$ and quantitative histograms of the ChIP assay (D for AP-1 and E for NF- $\mathrm{B}$ ). The results are presented as the mean \pm SEM of three independent experiments. Statistical significance: ${ }^{* * *} p<0.001$ vs. untreated control cells, \#\# $p<0.01$ and \#\#\# $p<0.001$ vs. O-1602-treated cells.

Table 1. Changes in body weight and plasma lipid profiles in mice.

\begin{tabular}{|c|c|c|c|}
\hline & $\begin{array}{c}\text { ND } \\
(n=5)\end{array}$ & $\begin{array}{c}\text { NFD } \\
(n=6)\end{array}$ & $\begin{array}{c}\text { HFD + CID } \\
(1 \mathrm{mg} / \mathrm{kg}) \\
(\mathrm{n}=5)\end{array}$ \\
\hline Body weight, $g$ & $35.9 \pm 0.8$ & $46.7 \pm 1.8^{* *}$ & $37.4 \pm 1.4^{\# \#}$ \\
\hline Glucose, mg/dL & $174.8 \pm 10.7$ & $287.3 \pm 22.8^{* *}$ & $212.7 \pm 55.1 \# \#$ \\
\hline Total cholesterol & $319.3 \pm 4.6$ & $927.6 \pm 45.9^{* * *}$ & $445.9 \pm 41.7$ \#\#\# \\
\hline LDL cholesterol & $212.6 \pm 9.9$ & $852.3 \pm 57.7^{* * *}$ & $333.6 \pm 55.6$ \\
\hline HDL cholesterol & $88.9 \pm 9.1$ & $52.8 \pm 9.7^{* *}$ & $98.7 \pm 9.4^{\# \# \#}$ \\
\hline Triglycerides & $79.3 \pm 12.0$ & $126.0 \pm 33.6^{* *}$ & $86.7 \pm 19.6$ \#\# \\
\hline
\end{tabular}

\section{Discussion}

In this study, we reported the following: (1) GPR55 activation by O-1602 induced monocyte adhesion to endothelial cells via Mac-1 expression; (2) Mac-1 expression is regulated by binding of the transcription factors AP-1 and NF- KB to the nt -750 to -503 promoter region of $\mathrm{Mac}-1$ in monocytes, (3) signaling cascades of GPR55 activation to 
Mac-1 gene expression are Gq/Ca ${ }^{2+} / \mathrm{CaMKK}$ and PI-3K, and (4) blockage of GPR55 protected against atherosclerosis progression along with improved lipid profiles, as shown in Figure 12. Therefore, our results are associated with several points, including monocyte adhesion, atherosclerosis protection, and improved lipid profiles.

A

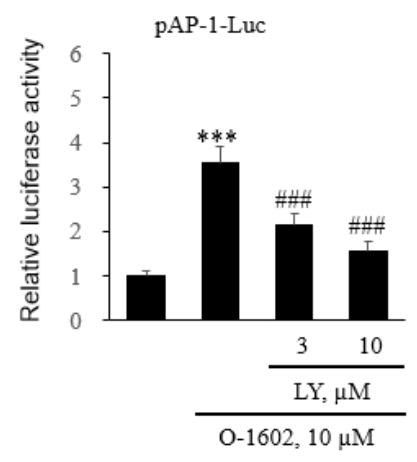

$\mathrm{C}$

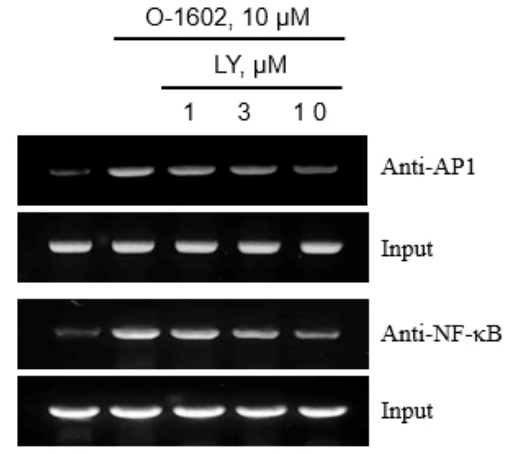

B

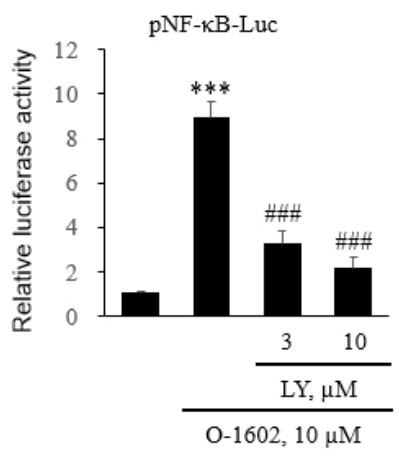

$\mathrm{D}$

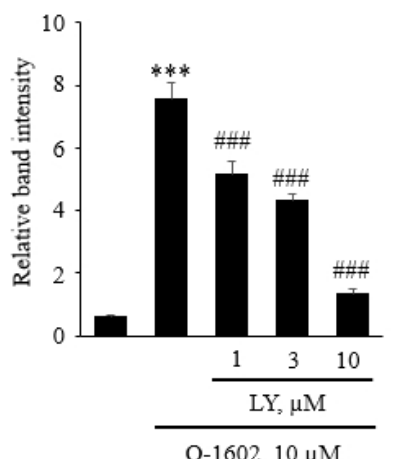

$\mathrm{E}$

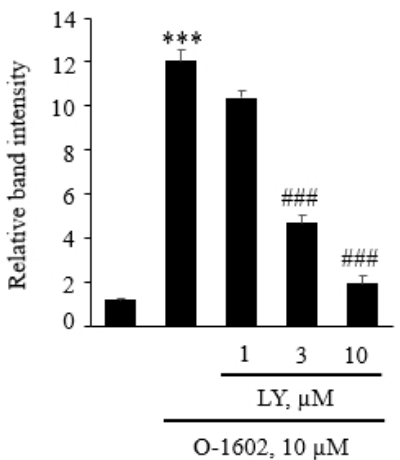

Figure 10. Effects of LY294002 on O-1602-induced expression of AP-1 and NF- $\kappa B$ in THP-1 cells. THP-1 cells were pretreated with the indicated concentrations of LY294002 for $1 \mathrm{~h}$, and then treated with $10 \mu \mathrm{M} \mathrm{O}-1602$ for $24 \mathrm{~h}$. Mac-1 mRNA, promoter activity, and protein expression were analyzed by reporter gene assay and chromatin immunoprecipitation (ChIP) assay. The AP-1 (A) and NF-B (B) luciferase activities are represented as the mean \pm SEM from five to six independent experiments. (C-E) Binding of AP-1 and NF- $\mathrm{KB}$ to the Mac-1 promoter was detected by ChIP assay. Representative images (C) and quantitative histograms of the ChIP assay (D for AP-1 and E for NF- $\mathrm{kB}$ ). The results are presented as the mean \pm SEM of three independent experiments. Statistical significance: ${ }^{* * *} p<0.001$ vs. untreated control cells, \#\#\# $p<0.001$ vs. O-1602-treated cells.

The adhesion of monocytes to endothelial cells by GPR55 activation has been extensively studied. This not only confirms the signaling cascade of GPR55 but also elucidates the adhesion molecule of Mac-1 expression and its promoter analysis. During the study, we found that O-1602-induced cell adhesion appears to result from the upregulation of Mac-1 surface expression in monocyte cells, making a firm association with ICAM-1 expression on the vascular endothelium [18]. Our results clearly showed that O-1602 induced Mac-1 mRNA and protein expression, as well as the activity of the Mac-1 promoter. Based on the experimental results and other reports on Mac- 1 expression at the transcriptional level $[22,23]$, we tried to identify the essential regulatory elements in the promoter region of the Mac-1 gene. We found that the essential region between $\mathrm{nt}-750$ and $-503 \mathrm{bp}$ contains consensus binding sites for AP- 1 and NF- $\mathrm{kB}$, and the ChIP assays confirmed that $\mathrm{O}-1602$ enhanced binding of AP-1 and NF- $\mathrm{KB}$ to the corresponding binding sites of the Mac-1 promoter. Thus, we discovered that $\mathrm{AP}-1$ and $\mathrm{NF}-\mathrm{KB}$ are essential transcription factors for O-1602-induced induction of Mac-1 transcription and subsequent monocyte adhesion. 


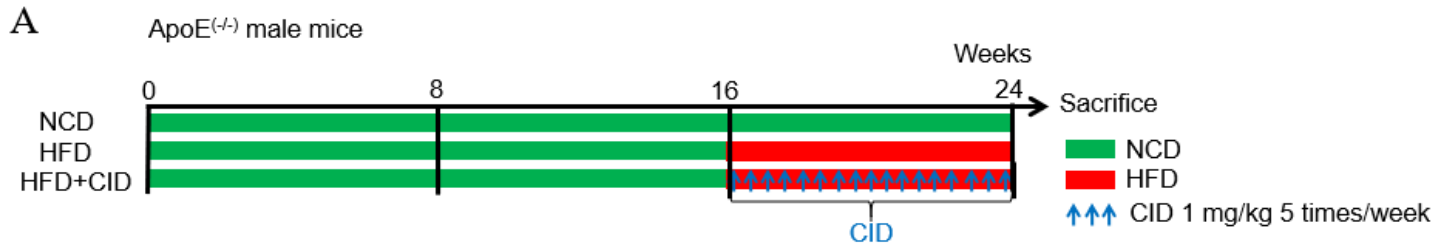

B

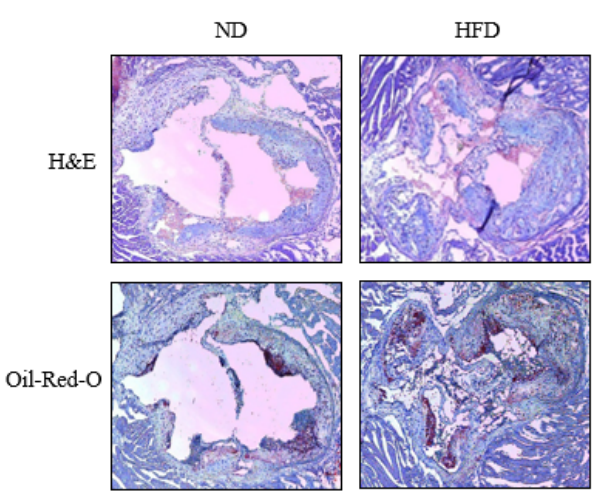

HFD + $\mathrm{CID}(1 \mathrm{mg} / \mathrm{kg})$

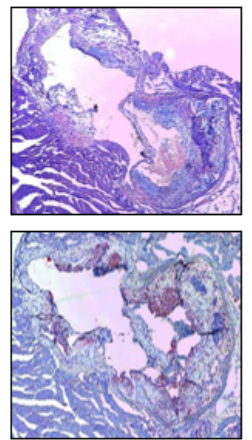

$\mathrm{C}$

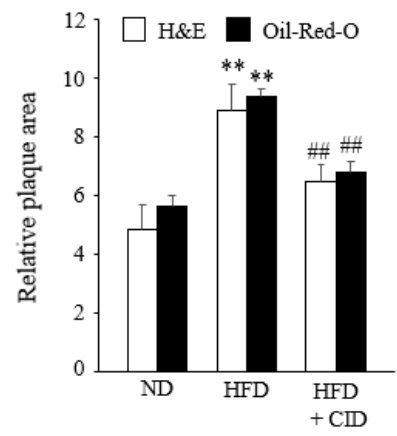

Figure 11. Effects of GPR55 blockage on atherosclerotic plaque formation in vivo. (A) High fat-diet (HFD)-induced atherosclerosis protocol. Sixteen-week aged $A p o E^{-/-}$mice were followed up for 8 weeks under normal chow diet (ND) or were fed with an HFD from 16 weeks to 24 weeks (HFD). Another group of mice, that is, the HFD plus CID16020046 group, was intraperitoneally treated with $1 \mathrm{mg} / \mathrm{kg}$ CID16020046, five times per week during HFD feeding before euthanasia. (B) Images of H\&E and oil red O staining in cross-sections of the aortic sinuses from the ND, HFD, or HFD plus CID16020046 groups. Representative images from five or six independent mice are shown. (C) Quantitative data are presented as the means \pm SEM of five or six independent mice. ${ }^{* *} p<0.01$ compared with an ND, \#\# $p<0.01$ compared with an HFD.

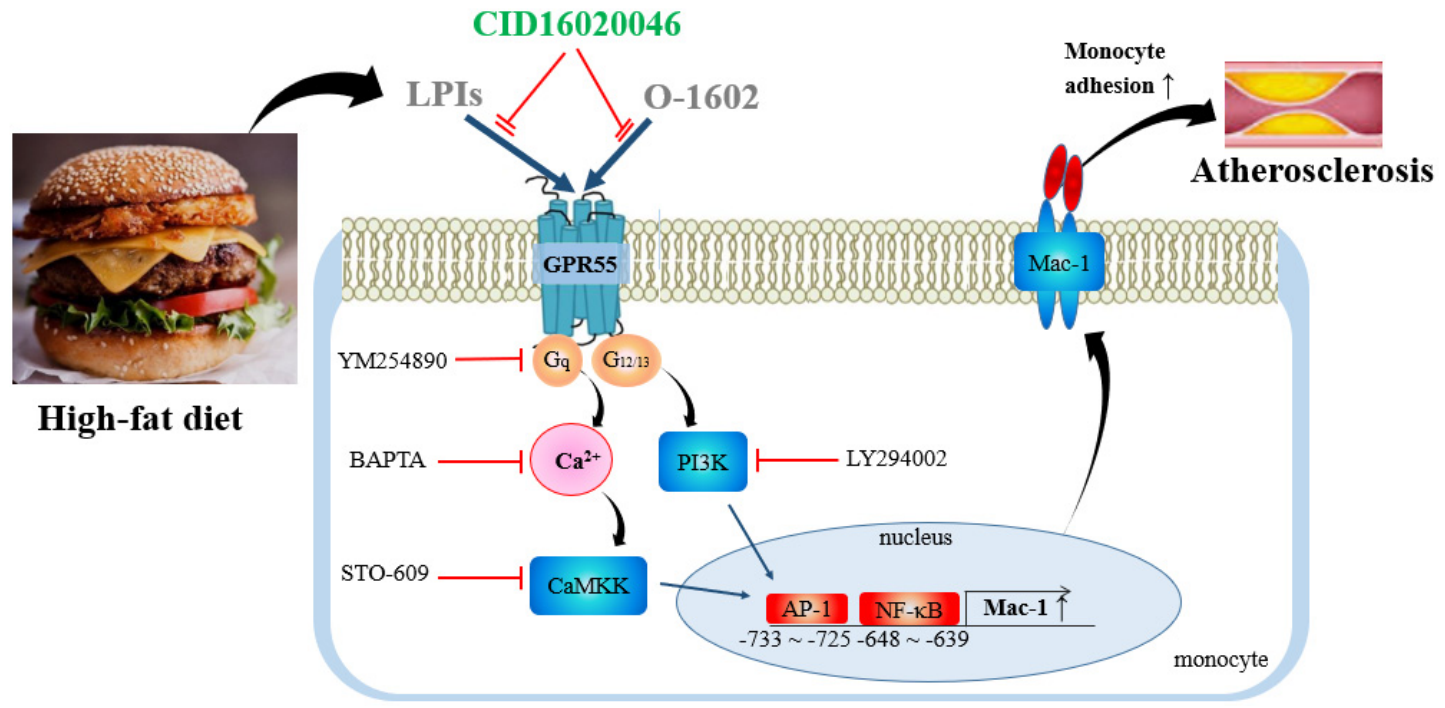

Figure 12. Proposed mechanism of GPR55 activation in monocyte adhesion and atherosclerosis development. Activation of GPR55 leads to Mac-1 induction through AP-1 and NF- $\mathrm{kB}$ by signaling cascades of Gq/Ca ${ }^{2+} / \mathrm{CAMKK}$ and PI3K. Increased Mac-1 expression enhances monocyte adhesion and atherosclerosis development. LPI, lysophopshatidylinositol.

The blockage of GPR55 by CID16020046 in vivo protects against atherosclerosis progression. The effect of CID16020046 on monocyte adhesion may partly explain the protection against atherosclerosis progression. Furthermore, previous studies have supported the in vivo results. For example, mRNA and protein levels of GPR55 were detected in human macrophages, and their expression were increased in foam cells [17]. Activation of GPR55 by O-1602 exacerbated oxLDL-induced lipid accumulation by upregulating CD36 and SR- 
$\mathrm{BI}$, while it reduced cholesterol efflux by downregulating ABC-A1 and ABC-G1 in human macrophages [17]. Activation of GPR55 by O-1602 also induced pro-inflammatory TNF- $\alpha$ and reduced anti-inflammatory IL-10 expression in human macrophages [17]. Therefore, blockage of GPR55 in macrophages and foam cells may suppress lipid accumulation and inflammatory responses in atherosclerotic plaques, strongly supporting the in vivo results of the present study. Furthermore, oxLDL increased GPR55 expression in human aortic endothelial cells [18]. CID16020046 protects against oxLDL-induced cell death, ROS generation, and secretion of pro-inflammatory cytokines such as IL-8 and MCP-1 in human aortic endothelial cells [18]. CID16020046 also suppressed oxLDL-induced expression of adhesion molecules VCAM-1 and E-selectin in human aortic endothelial cells [18]. These results from endothelial cells also support the pro-atherosclerotic roles of GPR55, which is consistent with the present findings of GPR55 blockage-induced protection against atherosclerosis progression.

Montecucco et al. reported that the CID16020046 treatment did not affect atherogenesis [24]. However, several points of CID16020046 treatment differed between the report and our experiment. They used a $0.5 \mathrm{mg} / \mathrm{kg}$ dose for 3 weeks in an 11-week high-cholesterol diet protocol, while we used a $1 \mathrm{mg} / \mathrm{kg}$ dose five times per week in an 8-week HFD protocol. We used a two-fold higher dose than the study of Montecucco et al. $(1 \mathrm{mg} / \mathrm{kg}$ vs. $0.5 \mathrm{mg} / \mathrm{kg}$ ) and used an HFD instead of high-cholesterol diets [24]. Therefore, a dose of $1 \mathrm{mg} / \mathrm{kg}$ seems to be optimal to achieve efficacy in vivo, which has recently been supported in an HFD-induced fatty liver model [25]. In addition, high-cholesterol diets were inadequate to activate GPR55, because lysophosphoinositols, the endogenous ligands of GPR55, are provided in an HFD but not in high-cholesterol diets $[25,26]$. Especially, levels of lysophosphatidylinositols of 18:0,18:1, 18:2, and 18:3 were significantly increased in the liver after HFD feeding [25]. Additionally, an HFD may provide other lipid agonists of GPR55, such as oleoylethanolamide and lysophosphatidylcholines [26-29].

Blockage of GPR55 by CID16020046 also improved lipid profiles in vivo. This may be due to the blockage of GPR55 in hepatocytes and adipocytes. Indeed, CID16020046 suppressed HFD-induced hepatic steatosis in mice, suggesting that increased lysophosphatidylinositols may be a cause of hepatic steatosis in overnutrition conditions [25]. In fact, serum levels of lysophosphatidylinositol species of 16:0, 18:1, and 18:1 isomers were found to be high in patients with non-alcoholic steatohepatitis [30]. Circulating lysophosphatidylinositol levels are increased in patients with non-alcoholic fatty liver disease [30]. Lysophosphatidylinositol augments lipid content by inducing de novo lipogenesis and decreasing $\beta$-oxidation [30]. In addition, lysophosphatidylinositol promotes the initiation of hepatic stellate cell activation by stimulating acetyl-coenzyme A carboxylase- $\alpha$ [30]. Similarly, the lysophosphatidylinositol-GPR55 system has been positively associated with human obesity [31]. Lysophosphatidylinositols increased the expression of lipogenic genes (fatty acid synthase and acetyl CoA carboxylase) and promoted adipocyte differentiation by increasing PPAR expression in visceral adipose tissues [28]. Furthermore, acute O-1602 administration induced hyperphagia, which was accompanied by decreased expression of the anorexigenic neuropeptide CART, and chronic O-1602 administration increased adiposity [32]. Increased expression of GPR55 in visceral adipose tissue and liver of obese patients might support the results of the present study and suggest GPR55 as a possible therapeutic target for improving lipid profiles [30,31].

In summary, this study provides important evidence that GPR55 blockage markedly inhibits HFD-induced atherosclerosis development and improves HFD-induced lipid profiles. Mechanistically, GPR55-mediated induction of Mac-1 expression was found to be regulated at the transcriptional level in monocytes by activation of the AP-1 and NF- $\mathrm{kB}$ pathways through $\mathrm{Gq} / \mathrm{Ca}^{2+} / \mathrm{CaMKK}$ and PI-3K. Collectively, these results suggest that GPR55 activation might be the key component responsible for the pro-atherosclerotic effects of the HFD. 


\section{Materials and Methods}

\subsection{Chemicals and Antibodies}

O-1602 and CID16020046 were purchased from Tocris Bioscience (Ellisville, MO, USA). R-phycoerythrin (PE)-conjugated mouse anti-human Mac-1 (clone ICRF44; BD) antibody (Cat No. 555388) and PE-conjugated mouse IgG isotype control (clone MOPC-21) antibody (Cat No. 555749) were obtained from BD Biosciences (San Diego, CA, USA). Various signal pathway inhibitors were purchased from EMD Serono (Rockland, MA, USA) and Sigma-Aldrich (St. Louis, MO, USA).

\subsection{Cell Culture}

THP-1 (a human monocytic leukemia cell line) cells were purchased from ATCC (Manassas, VA, USA). Cells were grown in RPMI 1640 medium (Life Technologies, Carlsbad, CA, USA) supplemented with 10\% heat-inactivated fetal bovine serum (FBS), antibioticantimycotic, and L-glutamine (Life Technologies). The HUVECs were obtained from Lonza Walkersville (Walkersville, MD, USA) and cultured in endothelial growth medium-2 (EGM$2 \mathrm{MV}$; Lonza). The cells were maintained at $37^{\circ} \mathrm{C}$ in a humidified atmosphere containing $5 \% \mathrm{CO}_{2}$ and $95 \%$ air.

\subsection{Animals and Diets}

The ApoE KO mice were purchased from Jackson Laboratories. Animals were allowed free access to tap water and laboratory rodent chow at $20-22{ }^{\circ} \mathrm{C}$ and $50-60 \%$ relative humidity. All animal procedures conformed to the Guide for the Care and Use of Laboratory Animals published by the US National Institute of Health (NIH Publication No. 85-23, revised 1996), and the experimental protocols were approved by the Pusan National University Institutional Animal Care and Use Committee. In this study, 16-week-old mice were randomly divided into three groups: control $(n=5)$, in which mice were fed a normal chow for 8 weeks; HFD, in which mice $(\mathrm{n}=6)$ were fed an HFD for 8 weeks; and HDF plus CID16020046, in which mice ( $\mathrm{n}=5)$ were fed an HDF for 8 weeks with CID16020046 $(1 \mathrm{mg} / \mathrm{kg}$ ) five days per week for the same 8 weeks (experimental scheme in Figure 11). The animal protocol used in this study was reviewed and approved by the PNU Institutional Animal Care Committee (PNU-IACUC) for compliance with the ethics of the procedures and animal care.

\subsection{Flow Cytometric Analysis}

To determine Mac- 1 protein expression, THP- 1 cells $(1 \times 105 / \mathrm{mL})$ were collected from cultures and washed with fluorescence-activated cell sorting (FACS) buffer (PBS containing $1 \%$ FCS and $0.05 \%$ NaN3). Cells were then incubated with FcR blocker (antihuman IgG; Sigma-Aldrich Co.) to block nonspecific antibody binding, and bound with PE-conjugated mouse anti-human Mac-1 (clone ICRF44; BD) with matched pairs of PEconjugated mouse IgG isotype control (clone MOPC-21) antibody. Analysis was performed using FACSCalibur and CELLQUESTPRO software (BD), which recorded 10,000 cells in each individual sample. Live cells were gated based on size (FSC) and granularity (SSC), and Mac-1 expression was analyzed.

\subsection{Adhesion Assay}

The THP-1 monocytes were labeled with $0.2 \mathrm{mg} / \mathrm{L}$ calcein-AM for $30 \mathrm{~min}$ at $37^{\circ} \mathrm{C}$, and labeled cells were seeded onto confluent HUVECs. After $2 \mathrm{~h}$, co-cultured cells were washed with $1 \times$ PBS containing $1 \%$ bovine serum albumin (BSA), and images were obtained using an inverse optical microscope (Axiovert 25) and Axio Vision Release 4.7 software (Carl Zeiss MicroImaging GmbH, Oberkochen, Germany). Localization data were quantified using ImageJ analysis. 


\subsection{RNA Isolation and RT-PCR}

Total RNA was isolated using TRIzol reagent (Life Technologies) and reverse transcribed using the Improm II reverse transcription system. The reverse transcribed cDNA was amplified by PCR using specific primers and conditions as previously described [33]. PCR products were separated on $1.2 \%$ agarose gels and stained with ethidium bromide solution.

\subsection{Preparation of Mac-1 Promoter Constructs}

Human genomic DNA was isolated from human macrophages using a DNeasy Tissue Kit. The $2 \mathrm{~kb} 5^{\prime}$-flanking promoter region from the genomic DNA was amplified by PCR using the upstream primer, $5^{\prime}$-ATT GGC GGT ACC ATA AAG GTG AGG TTT GTG-3', and the downstream primer, 5'-ATG CAC CTG CTA GCA GAA GGA CTC TCA GAG-3'; underlined are the sites of the restriction enzymes KpnI and NheI. Both primers were designed based on sequences retrieved from the GenBank Accession J03925. The amplified $2010 \mathrm{bp}$ fragment was cloned into the luciferase vector pGL4.10 Basic (Promega, Fitchburg, WI, USA). Additional deletion constructs lacking distal promoter sequences (denoted pMac1-Luc-1248, pMac1-Luc-750, pMac1-Luc-503, and pMac1-Luc-317) were prepared by the digestion of pMac1-Luc-2010 with the restriction enzymes BgIII, SacI, SspI, or NdeI. The Mac-1 promoter sequence was analyzed for any transcription factor binding sites within the $5^{\prime}$-flanking promoter region using the sequence motif search program devised by TFresearch (http:/ / mbs.cbrc.jp/research/db /TFSEARCH.html (accessed on 1 March 2021)).

\subsection{Chromatin Immunoprecipitation (ChIP) Assays}

The ChIP analysis was performed using the Millipore ChIP kit (Millipore, Billerica, MA, USA), following the manufacturer's instructions with minor modifications. For each assay, the THP- 1 monocytes were inoculated into a 10-cm dish (a total of $5 \times 106$ cells) and fixed with $1 \%$ formaldehyde. Cell pellets were resuspended in SDS lysis buffer containing protease inhibitors ( $1 \mathrm{mM}$ PMSF, $1 \mu \mathrm{g} / \mathrm{mL}$ aprotinin, and $1 \mu \mathrm{g} / \mathrm{mL}$ pepstatin A). The samples were sonicated with a Misonix sonicator 3000 (Misonix, Farmingdale, NY, USA), centrifuged, and diluted 10-fold in ChIP dilution buffer. After removing an aliquot (wholecell extract input), the chromatin samples were incubated at $4{ }^{\circ} \mathrm{C}$ overnight with antibodies against AP-1 (\#9165, Cell Signaling) or NF-KB (\#8242, Cell Signaling). The samples were then precipitated by binding to protein A-agarose/salmon sperm DNA beads (Millipore, Billerica, MA, USA). The immunoprecipitated chromatin was analyzed by PCR using primers for the Mac- 1 gene promoter. Cycling parameters were $58{ }^{\circ} \mathrm{C}$ for $1 \mathrm{~min}$ and $95^{\circ} \mathrm{C}$ for $30 \mathrm{~s}$, followed by 40 cycles.

\subsection{Transient Transfection and Luciferase Assay}

The THP-1 cells were grown to $90-95 \%$ confluence in 12-well plates. One microgram of plasmid DNA and $2 \mu \mathrm{L}$ of Lipofectamine LTX reagent (Invitrogen, Carlsbad, CA, USA) were separately diluted in $50 \mu \mathrm{L}$ of Opti-MEM medium (GIBCO, New York, NY, USA), mixed together, and incubated at room temperature for $30 \mathrm{~min}$. Cells were then washed with serum-free medium before adding $400 \mu \mathrm{L}$ of Opti-MEM medium, and then the diluted mixed solution was added to the cells. Plates were incubated at $37^{\circ} \mathrm{C}$ for $6 \mathrm{~h}$. Subsequently, the conditioned medium was removed, and the cells were grown in fresh medium containing 10\% FBS for $24 \mathrm{~h}$. Cells were untreated or treated with O-1602. Cell lysates were prepared using passive lysis buffer from Promega assay system (Promega, Madison, WI, USA) and were used to measure luciferase activity according to the manufacturer's instructions for the dual luciferase reporter assay (Promega, Madison, WI, USA). All firefly luciferase values were normalized to Renilla luciferase to compare transfection efficiencies. The results are presented as the mean \pm SEM of a representative experiment performed in triplicate. 


\title{
4.10. Statistical Analysis
}

The results are expressed as the mean \pm SEM of the number of experiments indicated in the figure legends. Statistical significance of differences was calculated using a one-way ANOVA with a Bonferroni post hoc test for multiple group comparisons or Student's unpaired t-test for two-group comparisons, where appropriate. The analyses were performed using GraphPad Prism Software version 5.02 (GraphPad Inc., La Jolla, CA, USA). Statistical significance was set at $p<0.05$.

Author Contributions: Conceptualization, S.-J.L. and D.-S.I.; methodology, formal analysis, investigation, and visualization, S.-J.L.; writing — original draft preparation, S.J.L.; writing-review and editing, D.-S.I.; funding acquisition, S.-J.L. and D.-S.I. All authors have read and agreed to the published version of the manuscript.

Funding: This research was funded by the Basic Research Laboratory Program (BRL) and the Basic Science Research Program of the Korean National Research Foundation funded by the Korean Ministry of Science, ICT and Future Planning (NRF-2020R1A4A1016142, NRF-2019R1A2C1011206, and NRF-2019R1A2C1005523).

Institutional Review Board Statement: The study was conducted according to the guidelines of the Declaration of Helsinki and approved by the PNU Institutional Animal Care Committee with respect to the ethics of the procedures and animal care (PNU-20192335).

Informed Consent Statement: Not applicable.

Conflicts of Interest: The authors declare no conflict of interest.

\begin{abstract}
Abbreviations
LDL: low-density lipoproteins; VCAM-1: vascular cell adhesion molecule 1; ICAM-1: intercellular adhesion molecule 1; Mac-1: macrophage-1 antigen; LFA-1: lymphocyte function-associated antigen-1; VLA-4: very late antigen-4; PSGL-1: P-selectin glycoprotein ligand-1; THC: tetrahydrocannabinol; HFD: high-fat diet; HUVEC: human umbilical vein endothelial cells; KO: knockout; CaMKK: $\mathrm{Ca}^{2+}$ / calmodulin-dependent kinase kinase; YM: YM254890; BAP: BAPTA-AM; STO: STO609; LY: LY294002; NF-кB: nuclear factor k-light-chain-enhancer of activated B cells; MCP-1: monocyte chemoattractant protein 1.
\end{abstract}

\section{References}

1. Frostegård, J. Immunity, atherosclerosis and cardiovascular disease. BMC Med. 2013, 11, 117. [CrossRef]

2. Greaves, D.R.; Gordon, S. Immunity, atherosclerosis and cardiovascular disease. Trends Immunol. 2001, 22, 180-181. [CrossRef]

3. Fenyo, I.M.; Gafencu, A.V. The involvement of the monocytes/macrophages in chronic inflammation associated with atherosclerosis. Immunobiology 2013, 218, 1376-1384. [CrossRef]

4. Mestas, J.; Ley, K. Monocyte-endothelial cell interactions in the development of atherosclerosis. Trends Cardiovasc. Med. 2008, 18, 228-232. [CrossRef]

5. Navab, M.; Hama, S.Y.; Nguyen, T.B.; Fogelman, A.M. Monocyte adhesion and transmigration in atherosclerosis. Coron. Artery Dis. 1994, 5, 198-204. [CrossRef]

6. Reglero-Real, N.; Colom, B.; Bodkin, J.V.; Nourshargh, S. Endothelial cell junctional adhesion molecules: Role and regulation of expression in inflammation. Arterioscler. Thromb. Vasc. Biol. 2016, 36, 2048-2057. [CrossRef]

7. Zhang, J.; Alcaide, P.; Liu, L.; Sun, J.; He, A.; Luscinskas, F.W.; Shi, G.-P. Regulation of endothelial cell adhesion molecule expression by mast cells, macrophages, and neutrophils. PLoS ONE 2011, 6, e14525. [CrossRef]

8. Jiang, Y.; Beller, D.; Frendl, G.; Graves, D. Monocyte chemoattractant protein-1 regulates adhesion molecule expression and cytokine production in human monocytes. J. Immunol. 1992, 148, 2423-2428.

9. Oka, S.; Nakajima, K.; Yamashita, A.; Kishimoto, S.; Sugiura, T. Identification of GPR55 as a lysophosphatidylinositol receptor. Biochem. Biophys. Res. Commun. 2007, 362, 928-934. [CrossRef] [PubMed]

10. Henstridge, C.M.; Balenga, N.A.; Ford, L.A.; Ross, R.A.; Waldhoer, M.; Irving, A.J. The GPR55 ligand L-alpha-lysophosphatidylinositol promotes RhoA-dependent $\mathrm{Ca}^{2+}$ signaling and NFAT activation. FASEB J. 2009, 23, 183-193. [CrossRef] [PubMed]

11. Lauckner, J.E.; Jensen, J.B.; Chen, H.Y.; Lu, H.C.; Hille, B.; Mackie, K. GPR55 is a cannabinoid receptor that increases intracellular calcium and inhibits M current. Proc. Natl. Acad. Sci. USA 2008, 105, 2699-2704. [CrossRef]

12. Oka, S.; Toshida, T.; Maruyama, K.; Nakajima, K.; Yamashita, A.; Sugiura, T. 2-Arachidonoyl-sn-glycero-3-phosphoinositol: A possible natural ligand for GPR. J. Biochem. 2009, 145, 13-20. [CrossRef] 
13. Kotsikorou, E.; Madrigal, K.E.; Hurst, D.P.; Sharir, H.; Lynch, D.L.; Heynen-Genel, S.; Milan, L.B.; Chung, T.D.; Seltzman, H.H.; Bai, Y.; et al. Identification of the GPR55 agonist binding site using a novel set of high-potency GPR55 selective ligands. Biochemistry 2011, 50, 5633-5647. [CrossRef]

14. Ryberg, E.; Larsson, N.; Sjogren, S.; Hjorth, S.; Hermansson, N.O.; Leonova, J.; Elebring, T.; Nilsson, K.; Drmota, T.; Greasley, P.J. The orphan receptor GPR55 is a novel cannabinoid receptor. Br. J. Pharm. 2007, 152, 1092-1101. [CrossRef]

15. Johns, D.G.; Behm, D.J.; Walker, D.J.; Ao, Z.; Shapland, E.M.; Daniels, D.A.; Riddick, M.; Dowell, S.; Staton, P.C.; Green, P.; et al. The novel endocannabinoid receptor GPR55 is activated by atypical cannabinoids but does not mediate their vasodilator effects. Br. J. Pharm. 2007, 152, 825-831. [CrossRef]

16. Chiurchiu, V.; Lanuti, M.; De Bardi, M.; Battistini, L.; Maccarrone, M. The differential characterization of GPR55 receptor in human peripheral blood reveals a distinctive expression in monocytes and NK cells and a proinflammatory role in these innate cells. Int. Immunol. 2015, 27, 153-160. [CrossRef]

17. Lanuti, M.; Talamonti, E.; Maccarrone, M.; Chiurchiu, V. Activation of GPR55 receptors exacerbates oxLDL-induced lipid accumulation and inflammatory responses, while reducing cholesterol efflux from human macrophages. PLoS ONE 2015, 10, $\mathrm{e} 0126839$.

18. Wang, Y.; Pan, W.; Wang, Y.; Yin, Y. The GPR55 antagonist CID16020046 protects against ox-LDL-induced inflammation in human aortic endothelial cells (HAECs). Arch. Biochem. Biophys. 2020, 681, 108254. [CrossRef] [PubMed]

19. Ross, G.R.; Lichtman, A.; Dewey, W.L.; Akbarali, H.I. Evidence for the putative cannabinoid receptor (GPR55)-mediated inhibitory effects on intestinal contractility in mice. Pharmacology 2012, 90, 55-65. [CrossRef] [PubMed]

20. Kargl, J.; Brown, A.J.; Andersen, L.; Dorn, G.; Schicho, R.; Waldhoer, M.; Heinemann, A. A selective antagonist reveals a potential role of $\mathrm{G}$ protein-coupled receptor 55 in platelet and endothelial cell function. J. Pharmacol. Exp. Ther. 2013, 346, 54-66. [CrossRef]

21. Sharir, H.; Abood, M.E. Pharmacological characterization of GPR55, a putative cannabinoid receptor. Pharmacol. Ther. 2010, 126, 301-313. [CrossRef]

22. Miller, L.J.; Schwarting, R.; Springer, T.A. Regulated expression of the Mac-1, LFA-1, p150, 95 glycoprotein family during leukocyte differentiation. J. Immunol. 1986, 137, 2891-2900.

23. Lee, S.J.; Baek, S.E.; Jang, M.A.; Kim, C.D. SIRT1 inhibits monocyte adhesion to the vascular endothelium by suppressing Mac-1 expression on monocytes. Exp. Mol. Med. 2019, 51, 1-12. [CrossRef]

24. Montecucco, F.; Bondarenko, A.I.; Lenglet, S.; Burger, F.; Piscitelli, F.; Carbone, F.; Roth, A.; Liberale, L.; Dallegri, F.; Brandt, K.J. Treatment with the GPR55 antagonist CID16020046 increases neutrophil activation in mouse atherogenesis. Thromb. Haemost. 2016, 116, 987-997.

25. Kang, S.; Lee, A.-Y.; Park, S.-Y.; Liu, K.-H.; Im, D.-S. O-1602 Promotes Hepatic Steatosis through GPR55 and PI3 Kinase/Akt/SREBP-1c Signaling in Mice. Int. J. Mol. Sci. 2021, 22, 3091. [CrossRef] [PubMed]

26. Im, D.-S. GPR119 and GPR55 as Receptors for Fatty Acid Ethanolamides, Oleoylethanolamide and Palmitoylethanolamide. Int. J. Mol. Sci. 2021, 22, 1034. [CrossRef] [PubMed]

27. Drzazga, A.; Sowinska, A.; Krzeminska, A.; Rytczak, P.; Koziolkiewicz, M.; Gendaszewska-Darmach, E. Lysophosphatidylcholine elicits intracellular calcium signaling in a GPR55-dependent manner. Biochem. Biophys. Res. Commun. 2017, 489, $242-247$. [CrossRef]

28. Drzazga, A.; Kristinsson, H.; Sałaga, M.; Zatorski, H.; Koziołkiewicz, M.; Gendaszewska-Darmach, E.; Bergsten, P. Lysophosphatidylcholine and its phosphorothioate analogues potentiate insulin secretion via GPR40 (FFAR1), GPR55 and GPR119 receptors in a different manner. Mol. Cell. Endocrinol. 2018, 472, 117-125. [CrossRef] [PubMed]

29. McKillop, A.M.; Moran, B.M.; Abdel-Wahab, Y.H.; Flatt, P.R. Evaluation of the insulin releasing and antihyperglycaemic activities of GPR55 lipid agonists using clonal beta-cells, isolated pancreatic islets and mice. Br. J. Pharm. 2013, 170, 978-990. [CrossRef]

30. Fondevila, M.F.; Fernandez, U.; Gonzalez-Rellan, M.J.; Da Silva Lima, N.; Buque, X.; Gonzalez-Rodriguez, A.; Alonso, C.; Iruarrizaga-Lejarreta, M.; Delgado, T.C.; Varela-Rey, M. The L- $\alpha$-Lysophosphatidylinositol/G Protein-Coupled Receptor 55 System Induces the Development of Nonalcoholic Steatosis and Steatohepatitis. Hepatology 2021, 73, 606-624. [CrossRef]

31. Moreno-Navarrete, J.M.; Catalán, V.; Whyte, L.; Díaz-Arteaga, A.; Vázquez-Martínez, R.; Rotellar, F.; Guzmán, R.; GómezAmbrosi, J.; Pulido, M.R.; Russell, W.R. The L- $\alpha$-lysophosphatidylinositol/GPR55 system and its potential role in human obesity. Diabetes 2012, 61, 281-291. [CrossRef] [PubMed]

32. Díaz-Arteaga, A.; Vázquez, M.; Vazquez-Martínez, R.; Pulido, M.; Suarez, J.; Velásquez, D.; López, M.; Ross, R.; de Fonseca, F.R.; Bermudez-Silva, F. The atypical cannabinoid O-1602 stimulates food intake and adiposity in rats. Diabetes Obes. Metab. 2012, 14, 234-243. [CrossRef]

33. Lee, S.J.; Choi, E.K.; Seo, K.W.; Bae, J.U.; Kim, Y.H.; Park, S.Y.; Oh, S.O.; Kim, C.D. 5-Lipoxygenase plays a pivotal role in endothelial adhesion of monocytes via an increased expression of Mac-1. Cardiovasc. Res. 2013, 99, 724-733. [CrossRef] [PubMed] 